CROSS-CULTURAL MOTHERING PRACTICES OF IMMIGRANT CHINESE WOMEN

FROM MAINLAND CHINA

by

Michal Baron, B.A., York University, 2009

Toronto, Ontario

A major research paper

presented to Ryerson University

in partial fulfillment of the

requirements for the degree of

Masters of Arts

in the Program of

Early Childhood Studies

Toronto, Ontario, Canada, 2010

CMichal Baron 2010 


\section{Author's Declaration}

I hereby declare that I am the sole author of this major research paper.

I authorize Ryerson University to lend this major research paper to other institutions or individuals for the purpose of scholarly research.

Signature

I further authorize Ryerson University to reproduce this major research paper by photocopying or by other means, in total or in part, at the request of other institutions or individuals for the purpose of Scholarly research.

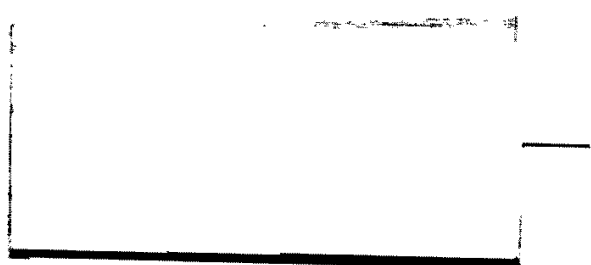




\title{
Cross-Cultural Mothering Practices of Immigrant Chinese Women from Mainland China
}

\author{
CMichal Baron 2010 \\ Masters of Arts \\ Early Childhood Studies \\ Ryerson University
}

\begin{abstract}
The purpose of this study was to examine how immigrant Chinese mothers of young children from Mainland China conceptualize parenting styles, based on their beliefs and values, and the impact of this in a new cultural context. A phenomenological approach was used with a convenience sample of five participants from Ontario, Canada. Three significant themes emerged: 1) behaviour modelling, 2) education, and 3) discipline. Results suggest culture plays a significant role in the value placed on education and discipline. Contrary to past research, Chinese-Canadian parenting styles were found to be flexible and to incorporate a high degree of warmth, care, and positive guidance through behaviour modelling.
\end{abstract}

Keywords: cross-cultural parenting, Chinese mothers, immigrants, behaviour modelling, authoritative parenting, authoritarian parenting, autonomous parental orientation, connectedness parental orientation, education, and discipline. 


\section{Acknowledgements}

First, I would like to thank my family and friends for supporting me in various ways during this past year. I would like to thank my lovely mother Rachel Nahir for always believing in me no matter the situation. I must also thank my dear friend Tamara Junkin, with whom I have shared over thirty-one years of experiences, for her consistent emotional and technical support. A special thanks to my husband for listening to my endless thoughts about the contents of this Masters Research paper. He has supported me on many levels throughout my education and I could not have achieved this milestone without him. I appreciate the support of my dear friends Gerald and Linda Reid for believing in me and taking care of me by providing me with warm meals and kind words.

A special thanks to my supervisor Dr. Judith Bernhard, Dr. Rachel Langford, and Dr. Kenise Murphy Kilbride for supporting and assisting me with various sections and focus of the MRP. I am forever grateful for their tireless efforts in assisting me. Finally, I am thankful to my second reader, Dr. Kim Snow, for the role model that she has been to me and for providing support for this paper. 


\section{Table of Contents}

Introduction 1

Purpose of the Study $\quad 3$

Research Question 3

$\begin{array}{ll}\text { Cultural Framework } & 4\end{array}$

$\begin{array}{ll}\text { Literature Review } & 6\end{array}$

$\begin{array}{lr}\text { Cultural Models of Parenting } & 6\end{array}$

$\begin{array}{ll}\text { Chinese Cultural Models of Parenting } & 8\end{array}$

Authoritative, Authoritarian, and Permissive Parenting Styles 9

Autonomous and Connectedness Parental Orientations $\quad 13$

$\begin{array}{lr}\text { Immigrant Families } & 15\end{array}$

$\begin{array}{ll}\text { Methodology } & 21\end{array}$

Reliability and Validity in Qualitative Research 22

$\begin{array}{ll}\text { Research Design } & 23\end{array}$

$\begin{array}{ll}\text { Sample and Setting } & 26\end{array}$

$\begin{array}{ll}\text { Data Collection } & 28\end{array}$

$\begin{array}{ll}\text { Data Analysis } & 30\end{array}$

$\begin{array}{ll}\text { Results } & 33\end{array}$

$\begin{array}{ll}\text { Behaviour Modelling } & 35\end{array}$

Modelling and Habit Formation 36

Modelling and Mutual Respect 36

$\begin{array}{lll}\text { Education } & 37\end{array}$

$\begin{array}{ll}\text { Discipline } & 39\end{array}$ 
Discussion

Behaviour Modelling

Education

Discipline

Limitations and Recommendations for Future Research

Conclusion

Table 1: Background of Chinese Mothers and their Children

Table 2: Background of Chinese Mothers and their Spouses

Appendix A Flyer

Appendix B Consent Agreement

Appendix C Interview Questions

References 


\section{Introduction}

Culture and parenting go hand in hand. The child rearing practices that parents implement, either consciously or unconsciously, are shaped to some degree by the beliefs and values of their culture (Bernhard, 1995). Bernhard (1995) suggested that in order to fully understand human development, and therefore parenting practices that foster this development, qualitative differences between and among culturally diverse groups must be recognized and studied more rigorously. The assortment of cultural differences ranges from biological to social influences on behaviour, and plays a significant role in every aspect of people's lives (Bernhard, 1995). For example, these differences even affect how immigrants perceive their new surroundings, which creates differences in attitudes to parenting.

To date, most cross-cultural research has employed quantitative research methods with diverse cultures in search of qualitative differences (Ratner \& Hui, 2003). Most cross-cultural psychologists have recognized that test materials and conditions must be sensitive to people's social environment, but researchers tend to ignore this and continue to use artificial and unfamiliar materials with diverse populations (Ratner \& Hui, 2003). Ratner and Hui (2003) clearly summarized these points in the following quote: "Positivist principles of measurement and analysis demand simple, unambiguous, manipulable, quantifiable stimuli, which elicit simple, quantitative responses" (p. 79).

Many researchers have applied positivist principles of measurement and analysis to cross-cultural research on parenting styles and orientations. For example, several researchers have implemented Baumrind's (1978) typology of configurational parenting styles to the study of Chinese parenting (Chao, 1994; Chuang and Su, 2009a; Lim \& Lim, 2004; Liu \& Guo, 2010). Other researchers have studied Chinese parents' value orientations in the realm of autonomous 
and connectedness orientated behaviours (Keller et al., 2006; Lin \& Fu, 1990; Liu et al., 2005). Overall, when taken together and compared, the conclusions of these studies are inconsistent.

A limited number of qualitative studies has been conducted on how immigrant Chinese mothers negotiate their cultural values and orientations in new cultural contexts (Lim \& Weiling, 2004). Some researchers have implemented qualitative and mixed research methods in order to understand how immigrants from around the world evaluate, perceive, and reconceptualise their roles as parents in their new cultural contexts (Ali, 2008; Anisef, Kilbride, Ochocka \& Janzen, 2001; George, Tsang, Man, \& Da, 2000; Lim \& Weiling, 2004). Ali (2008) conducted a qualitative study of the experiences of newcomer parents. One of the major findings was that parenting experiences varied as a function of the human, social, and cultural capital the newcomers brought with them. In addition, the results from this study suggested that newcomer parents felt a loss of their own parenting self-efficacy and attributed it to their inability to protect their children from the hardships faced as immigrants in school and society in general. The richness of the explanations of the parents' perceptions of these experiences, and the descriptions of their loss of parenting self-efficacy, were the outcome of the qualitative research methods used.

Javo, Alapack, Heyerdahl, and Ronning (2003) argued that qualitative research methods allow the researcher to delve more deeply into the culturally-based variances apparent in participants' descriptions of the value and meaning that they give to a particular childrearing phenomenon under study (Javo, Alapack, Heyerdahl, \& Ronning, 2003). 


\section{Purpose of the Study}

The purpose of this study is to explore how culture shapes the values and beliefs which inform parenting practices of immigrant Chinese women from Mainland China. In addition, a subsidiary purpose of this study is to discover how mothers conceptualize their parenting values and beliefs in their new cultural context. Through a qualitative approach, rich descriptions of how mothers' culturally informed values and beliefs shape their parenting practices were attained.

\section{Significance of the Study}

This study aims to display how the lines between culture and parenting values and beliefs are neither separate nor clearly drawn. It seeks to understand how immigrant parents negotiate and reconceptualise their parenting values and beliefs in a new cultural context. In order to understand how culture and living in a new cultural context informs parenting practices, it is important to get rich descriptions, in the form of narratives, from the participants under study. Therefore, I have implemented a qualitative research methods design to give mothers the opportunity to share their thoughts, ideas, and perceptions about how they view their culturally contextualized parenting practices.

\section{Research Question}

The main research question that guided this study was: How do the cultural values and beliefs of immigrant Chinese women from Mainland China shape the way they parent? The subsidiary question of this study was: How does a new cultural context influence these mothers' parenting practices? The following section introduces the framework which guided the philosophical underpinnings of the study. The purpose of including the framework was to assist the reader in understanding how the subject matter was conceptualised. 


\section{Cultural Framework}

In her book, Rogoff (2003) argued that developmental research to date lacks relevance to many nations because it makes generic claims regarding children's developmental skills and timelines, without understanding the cultural contexts of the specified nations. Furthermore, she argued that most research related to child development comes from middle class communities in North America and Europe, which house only a small proportion of the world's population (Rogoff, 2003). Rogoff (2003) asserted that the imposition by the researcher of value judgments from his or her own community onto another which the researcher is studying, especially if these impositions are negative, must be seen as ethnocentric. Ethnocentric opinions and assertions are value judgments that stem from uninformed, preconceived notions because they generalize from specified behaviours of a certain culture to related behaviours in other cultures without taking into account the meaning and contexts of the behaviours in these other communities (Rogoff, 2003).

In line with Rogoff's (2003) criticism that much of the developmental research to date focuses on North American and European middle class communities, Lam (2005) argued there is a lack of research on minority adolescent development. His study, conducted with parents and adolescents rather than parents and young children, is included in my study because it is one of the few I have found that implemented qualitative research methods relevant to the perceptions of Chinese parents. Lam (2005) asserted that traditional research on adolescent development failed to identify important aspects of the environment in which minority youth grow to adulthood. The varying philosophical, ideological, historical, and cultural contexts which are more likely dominant in the Western construction of autonomous self are not necessarily so in 
the Chinese cultural system (Lam, 2005). Support for importance of this major difference was demonstrated in Lam's (2005) qualitative study.

Eleven Chinese adolescents and their parents were recruited for Lam's (2005) study. All participants revealed how their Chinese cultural beliefs shaped their attitudes towards adolescent development. Results suggested that desired outcomes of adolescent development, according to the participants, could be grouped under four major categories: 1) be a good person (conduct/moral attributes), 2) be a good child (family-related attributes), 3) be a self-reliant person to honour family (academic/achievement-related attributes), and 4) be a mature person (other-related or other-directed attributes) (Lam, 2005). These findings were congruent with the depiction of the ideal person according to Confucian thought, which Lam (2005) argued was prevalent among many Chinese individuals, including those who have immigrated to North America. The results of Lam's (2005) study strengthen the findings of another recent study (Javo et al., 2003) that culturally contextualized research, employing qualitative research methods helps clarify how the specific cultural meaning given to a construct or idea is congruent with the holistic world of the people in the culture under study. 


\section{Literature Review}

\section{Cultural Models of Parenting}

In the recent decade, some researchers have been addressing parenting in a more culturally contextualized manner. For example, Tamminen (2006) argued that the cultural aspects of research and practice in the field of infant mental health should always be considered. Culture-specific research is especially crucial for people who are working with parents raising young children in a new cultural context because a cultural mismatch could exist between the beliefs and adaptive practices of the host and home cultures of the parents. A mismatch between the values and beliefs of the host and home cultures could create unnecessary stress within the parent-infant relationship (Tamminen, 2006).

Carlson and Harwood (2003) argued that a single, universal definition for maternal sensitivity was insufficient. They recruited middle-class, Puerto Rican mothers from San Juan, Puerto Rico $(n=28)$ and Anglo American $(n=32)$ mothers and their infants from the eastern region of Connecticut in the United States. Three in-home visits were made in which motherinfant interactions were videotaped and mothers interviewed about their parenting beliefs and practices. The results rated Puerto Rican mothers significantly higher on the use of feed/teach physical control at four, eight, and twelve months compared to Anglo-American mothers. In contrast to the general notion that secure attachment is affected negatively by physical control, this study found that secure attachment at twelve months was correlated with higher levels of physical control in the Puerto Rican infant-mother dyad sample, but not in the Anglo American sample (Carlson \& Harwood, 2003).

In an attempt to offer a more flexible explanation relevant to culture and parenting style categories, Keller et al. (2006) ran a cross-cultural study that explored the notion of cultural 
models (independent, autonomous-related and interdependent models) that emphasized parenting practices related to face-to-face contact and object play between mothers and their infants. First, parental ethno-theories, that is, a community's shared beliefs about the goals of child development and how to achieve them, were measured by incorporating a self-report that included a list of ten statements that depicted and described both autonomous (five items) and relational (five items) parenting styles. Parental ethno-theories are influenced by the cultural models prevalent in the parents' surroundings. Second, socialization goals were assessed by ten statements (Likert-type scale) of qualities that a child should learn by the age of three. Finally, family cohesion was measured by examining twenty-one studies on a Likert-type scale according to their degree of family cohesion. The Family Allocentricism Scale (Lay et al., 1998), measured family cohesion from parental self-reports. Two hundred and four mothers of three-month-old infants from Germany, United States (European decent), Greece (independent model group), China, Costa Rica, India (urban), Mexico (autonomous-related model group), Cameroon and India (rural) (interdependent model group) participated in this study. Mothers from the independent cultural group model scored lowest on family allocentrism, relational-socialization goals, and relational-parenting ethno-theories. Participants with an interdependent cultural model scored highest on those scales. The autonomous-related cultural model group (including Chinese mothers) occupied an intermediate position, marking them as neither completely autonomous nor relatedness orientated in their values and parenting practices (Keller et al., 2006). Although Keller et al. (2006) applied a quantitative research approach to cross-cultural parenting practices they did so in an extremely comprehensive manner by including many different cultural groups and a variety of relevant constructs. 
For Chinese parents, the ethical and philosophical system of Confucianism prevalent in China shapes the manner in which parenting goals, attributions, and strategies are shaped and utilized. According to Cheah and Rubin (2003) the philosophical doctrine of Confucianism promotes social harmony and cohesiveness of the group; they hypothesized that in line with a more traditional Confucianism-influenced parenting style, Chinese mothers would be more instructive and directive in their socialization tactics than their European-American counterparts. In contrast, the authors hypothesized that European-American mothers in their sample would provide a greater proportion of modelling strategies than their Chinese counterparts.

European-American $(n=103)$ and Chinese $(n=100)$ mothers of toddlers were recruited for this study. Self-report questionnaires were given to measure parents' goals for their children's social development, causal attributions that parents made of those skills, and the socialization strategies which parents believed were most effective for helping with, sharing, and controlling negative emotions. Overall, the authors' hypotheses were supported that Chinese mothers were more likely to endorse directive strategies, higher proportions of training, and education, significantly more than the European-American mothers. In contrast, European-American mothers replies showed they were more likely to support proactive modelling socialization strategies (Cheah \& Rubin, 2003).

\section{Chinese Cultural Models of Parenting}

In the last couple of decades, the characteristics of the Chinese immigrant population have been significantly different from that of their earlier counterparts from Hong-Kong and Taiwan (Guo \& DeVoretz, 2005). Most of the recent newcomers from China speak Mandarin. The Chinese are the largest visible minority group in Canada $(1,029,400)$ (Statistics Canada, 
2003) and it is important that society understand the differences among the large Chinese population, as they are not a homogenous group.

The increase of immigration from Mainland China to Canada and the United States has sparked cross-cultural research endeavours with Chinese families (Guo \& DeVoretz, 2005). Some researchers have implemented Baumrind's (1978) typology of configurational parenting styles to Chinese parenting styles (Chao, 1994; Chuang and Su, 2009a; Lim \& Lim, 2004; Liu \& Guo, 2010). Other researchers have studied Chinese parents' value orientations in the realm of autonomous- and connectedness- orientated parental behaviours (Keller et al., 2006; Lin and Fu, 1990; Liu et al., 2005). The following section introduces Baumrind's (1978) typology of configurational parenting, the discrepancies in the literature regarding the use of this typology to classify Chinese parents, and the inconsistent results that are evidenced in some studies related to the categorization of Chinese parents as discretely autonomous or connectedness oriented in their parental behaviours.

\section{Authoritative and Authoritarian Parenting Styles.}

Baumrind's (1978) typology of configurational parenting styles offers three distinct categories of parenting styles: authoritarian, permissive, and authoritative. Parents that have an authoritarian parenting style enforce punitive and forceful measures in attempt to reduce or eliminate the development of their children's independence. They believe that children should remain submissive and therefore they attempt to restrict their children's autonomy. These parents may be concerned and protective over their children, or they may be neglectful. Parents who have a permissive parenting style are believed to behave in an overly accepting and gentle manner towards their children's impulses and actions. These parents see themselves as resources for their children rather than active agents. Permissive parents are either very protective or overly 
self-involved, giving their children freedom as a way of escaping responsibility. Finally, parents who have an authoritative parenting style are believed to direct their child's behaviour and help shape the child's personality by using rational logic and guidance. Authoritative parents converse with their children in a collaborative way and encourage the development of an autonomous self. The authoritative parenting style is believed to foster discipline and social competence in a Western society (Baumrind, 1978).

S. Lim and Lim (2004) discussed the differences between the manner in which researchers conceptualize parenting styles by defining them as either configurational or orthogonal approach; they demonstrate how the approach that parents choose influences the manner in which they operationalize constructs relevant to parenting. An orthogonal approach to parenting styles measures and classifies parenting styles along separate key dimensions like warmth or concern, and control or restrictiveness. In contrast, a configurational approach measures and classifies parenting styles according to a set of attributes such as values, behaviours, and attitudes. S. Lim and $\operatorname{Lim}(2004)$ argued that orthogonal approaches to crosscultural studies are more meaningful because they investigate various parenting styles separately. In addition, they suggested that future studies should not be limited to Baumrind's (1978) typology of configurational parenting styles and researchers should be mindful of highly specific cultural constructs when studying diverse cultural populations ( $\operatorname{Lim} \& \mathrm{Lim}, 2004)$.

Chao (1994) raised questions about the relevance of Western typologies of parenting styles as early as 1994 . Inconsistent with the idea that Chinese parents are more authoritarian than Westerners in their parenting practices, Chuang and $\mathrm{Su}(2009 \mathrm{~b})$ found Chinese-Canadian parents balanced their parental authority with their children's needs and sought advice on 
parenting strategies from professionals, friends, and books, finding them very open minded and flexible in their parenting practices.

Chao (1994) claimed the concepts of authoritative and authoritarian parenting styles are ethnocentric in nature, and that they are irrelevant to the parenting styles and practices of most Chinese parents. Chao (1994) used the relationship that exists between authoritarian parenting and low school performance in Western children but not in Chinese children as an example, since for them the exact opposite relationship occurred (higher authoritarian parental qualities and higher school performance). Chao (1994) asserted that training a child according to Chinese cultural norms is not the military style of parenting perceived by many Westerner parents. In contrast to the cold nature of military training, Chinese parental styles incorporate high levels of involvement, care, concern, and physical closeness, which are prevalent in most Chinese families (Chao, 1994).

Chen et al. (1998) also highlighted the paradoxical findings between Canadian-born and Chinese-born children in relation to inhibitory behaviour. For this study, Chen et al. (1998) recruited Chinese-toddler dyads from two cities in China $(n=150)$ and Canadian-toddler dyads $(n=108)$ from southwestern Ontario, $97 \%$ of whom were Caucasian. Each mother completed the Child-Rearing Practices Report Q-Sort (CRPR; Block, 1981), with items describing childrearing attitudes, values, beliefs, and behaviours. Chen et al. (1998) constructed indexes of acceptance (e.g., "My child and I have warm, intimate times together."), rejection (e.g., "I often feel angry with my child."), encouragement of achievement (e.g., "I think a child should be encouraged to do things better than others." ), and punishment orientation (e.g., "I believe physical punishment to be the best way of disciplining.") Each pair of mother-toddler dyads participated in experimental conditions including a mother-child play session, an independent free-play session 
(child played alone while mother completed forms), and a stranger-play session (stranger introduces toys in attempt to attract toddler to play with him/her). A child's reluctance to play with the stranger was labelled "behavioural inhibition" and it was measured by the amount of time the toddlers spent with their mothers during the free-play session compared with the amount of time it took the toddlers to engage in play with the stranger (Chen et al., 1998).

Results displayed differences relevant to the association between child inhibitory behaviour and the mothers' punishment orientation. More specifically, child inhibitory behaviour was positively associated with the degree of the mother's attitude towards punishment in the Canadian sample. In contrast, child inhibitory behaviour was positively associated with mothers' warm and accepting attitudes towards their children in the Chinese sample (Chen et al, 1998). Although this study was conducted twelve years ago, it is included in this paper because it displays how a construct, in this case inhibitory behaviour, when measured together with another, in this case maternal beliefs on childrearing, can produce exactly the opposite findings in people from different cultures. The results from Chen's et al. (1998) study help to warn researchers of the importance of inquiring about the meaning and source of constructs in a specific culture before applying them to a cross-cultural study.

Some researchers have implemented Baumrind's (1978) typology of parenting styles to study Chinese parenting styles. Inconsistent results for Chinese mothers' parenting styles have been found in such studies (Chuang \& Su, 2009a; Liu \& Guo, 2010). For example, Chuang and Su (2009a) explored the concept of authoritarian/authoritative parenting styles in their study in one hundred and twenty-six Chinese families (sixty-seven Chinese-Canadian and fifty-nine Mainland Chinese). Characteristics of authoritarian parenting according to Western definitions include high power parental behaviour, minimal information exchanges with children, and low 
incidence of positive comments from parents. Results from this study, however, displayed results which were inconsistent with Baumrind's description of authoritarian/authoritative parenting styles. More specifically, Chuang and Su found no relationship between Chinese parents' low power strategies and positive comments. (Chuang \& Su, 2009a).

Similarly, G. Liu and Guo (2010) centred their study on the parenting styles of Chinese mother-child dyads ( $\mathrm{n}=39$ ) (mid-sized city in south-east China) and Canadian mother-child dyads $(n=40)$ in a small city in southern Ontario. The authors applied an observation paradigm in which mother-infant dyads were observed and assessed for two fifteen-minute free-play sessions in which mothers' and children's behaviours in completing tasks (castle building, math, and reading) were assessed. The authors found that both groups of mothers displayed more authoritative than authoritarian behaviours with their children (Liu \& Guo, 2010).

\section{Autonomy and Connectedness-Orientated Parental Behaviours.}

Supporting the idea that more cross-cultural studies should be conducted with the Chinese in various locations, Keller et al. (2006) pointed out that studies on cross-cultural parenting practices to date, specifically between Chinese and European-American families, have some methodological and theoretical weaknesses. One of these weaknesses is also related to the reliance on such broad categories as Baumrind's authoritative/authoritarian/permissive styles of parenting (Keller et al., 2006). Keller et al. (2006) designed a study that assessed what the authors called "parental ethno-theories." Parental ethno-theories are the parental beliefs and practices which parents hold and which are influenced by cultural models of childrearing prevalent in the parents' surroundings. Free-play interactions and interview data were examined, from forty-two mothers and their three-month-old infants in the cities of Beijing, Taiyuan, and Los Angeles. Studies focused on family allocentrism (parental self-reports of family cohesion), 
parenting systems related to primary care, discourses during mother-infant interactions, parenting systems in the ethno-theory interviews, and discourse in the ethno-theory interviews (Keller et al., 2006). Chinese mothers scored significantly higher on family allocentrism and used autonomy-related categories less often than Euro-American mothers. In addition, significant differences were found in the manner in which parenting systems (body contact system, body stimulation system, object stimulation system and face-to-face system) were discussed by mothers during interviews. Chinese mothers discussed body contact more than Euro-American mothers did and Euro-American mothers discussed object stimulation more than Chinese mothers (Keller et al., 2006).

Liu et al. (2005) conducted a study related to autonomy versus connectedness-orientated parenting behaviours with a sample of two hundred and twelve Chinese (Beijing) and Canadian mothers of toddlers. Autonomous orientations in relation to childrearing focus on fostering a more independent self in children. In contrast, orientations towards a connected self in the child encourage a relational self with more physical contact between parent and child. An event sampling approach was used to measure maternal socialization, goal-orientated behaviours focused on encouragement of autonomy or connectedness, maternal behaviours that served to promote autonomy or connectedness, and child initiation and exploration when playing independently or with his/her mother (Liu et al., 2005). Results suggested that Chinese children spent less time engaged in autonomous activities and displayed more connectedness to their mothers. This was reflected by the frequency, initiation, and duration of their connectedness-type behaviours. A significant difference for country was found. Chinese mothers scored significantly higher than their counterparts on encouragement of autonomy and connectedness type maternal 
behaviours. These results point to the idea that Chinese mothers spend more time socially engaging with their children than Canadian mothers (Liu et al., 2005).

In their study, Lin and Fu (1990) compared child rearing practices among Chinese, immigrant Chinese, and Caucasian-American parents on measures of parental control, encouragement of independence, and emphasis on achievement. Both groups of Chinese parents rated higher on encouragement of independence of their children than the Caucasian-American parents. Both Chinese and immigrant Chinese fathers had higher ratings on parental control, encouragement of independence, and emphasis on achievement than Caucasian-American fathers. In general, Chinese fathers were more involved with their children than the CaucasianAmerican fathers (Lin and $\mathrm{Fu}, 1990)$.

Although the aforementioned study was conducted roughly twenty years ago, it was included for two reasons. First, very few recent research studies include and compare fathers from Chinese-American, Chinese, and Caucasian-American descent. In addition, this study shows how cultural generalizations about the nature of independence versus connectedness vary across cultures, and must be studied more rigorously.

\section{Immigrant Families}

Familial stress is increased when a family immigrates to a new place, particularly when a cultural mismatch exists between the personal and cultural values and beliefs between the home and host country (Tamminen, 2006). Following from this line of reasoning Keller and Greenfield (2000) suggested a better integration of a developmental psychological approach into crosscultural psychology could enhance the future of the field both from a theoretical and empirical perspective. It follows that the marriage between these two branches of psychology could 
contribute to a boost in the frequency of research endeavours that are increasingly culturally sensitive and comprehensive in nature (Keller \& Greenfield, 2000).

Mel'endez (2005) discussed the importance of conducting more research related to the interaction of culture and parenting practices, including the impact of immigration, that support self-regulation in young children. Cross-cultural differences, which are assumed to be adaptive responses meant to support the acquisition of self-regulatory capacities, may not be viewed similarly across cultures. Changes in the socio-cultural milieu may cause stress to parents in this predicament. Therefore practitioners who encounter these newcomer families with young children must understand the complexities faced by the newcomers (Mel'endez, 2005).

In her study Ali (2008) explored the question, how do immigrant parents of young children experience their early settlement in Canada? The author conducted forty-two focus group sessions and forty-two individual interviews with mothers and fathers who had at least one child below the age of eight, were from one of seven ethnic communities (Amharic, Arabic, Dari, Mandarin, Somali, Twi and Urdu) and resided in Toronto, Montreal, or Vancouver. Ali (2008) found parenting experiences varied as a function of the human, social, and cultural capital that newcomers brought with them. In addition, newcomer parents felt a loss of their own parenting self-efficacy and attributed it to their inability to protect their children from the hardships faced as a newcomer in school and society in general. Parents discussed their children's hardships in school related to isolation and discrimination from other children. Furthermore, parents worried their children could not seek help from their teachers due to their difficulties in expressing themselves in the English language. Many parents also discussed how they could not enrol their children in extracurricular activities due to lack of finances, time, and energy. Parents tended to blame themselves for their incapacity to meet their perceived parental 
obligations and attributed this to their own reduced financial, social, and emotional resources in the face of enhanced demands placed on them in their new environment (Ali, 2008). Finally, one parent in Ali's (2008) study talked about how he was unable to guide and direct his adolescent son properly in the new Canadian system. His son had figured out the Canadian system and had taken advantage of the fact that his father was unaware of the rules and laws surrounding parental disciplinary actions in Canada and was afraid to reprimand his son for his negative behaviour (Ali, 2008).

In their study, Portes and Borocz (1989) presented a model of migration that incorporated not only the aspect of the social capital that immigrants brought with them to the host culture but also the manner in which any migrants new to the country were received by the host culture. The three types of reception outlined by the authors were low, neutral, and advantaged receptivity. Low receptivity by the host culture occurs when immigrants do not receive political asylum or any other form of legal status from the host culture. They are subject to discrimination and usually engage in low-wage manual labour with little to no opportunities for upward mobility. They are vulnerable to maltreatment in the forms of racism and stereotyping by the population of the host culture. Despite the human capital brought to the host country such as needed professional skills, if the newcomers fall into the low receptivity category then they may well find only manual labour. Neutral receptivity by the host culture occurs when immigrants are admitted to a country with legal status and have the opportunity to enter into appropriate careers. Finally, the advantaged receptivity category offers opportunities to immigrants to reach positions of local prominence (Portes \& Borocz, 1989). Portes and Borocz's (1989) study suggested that the success of immigrants in a new country is dependent on the level of receptivity they find upon arrival. 
Anisef, Kilbride, Ochocka, and Janzen (2001) conducted a qualitative study that centred on newcomer parents' perceptions of the existing supports that were offered to them upon arrival in Canada. The research questions were based on parental orientation, parenting styles, Canadian context (similarities and differences in parenting between home and host country), modification (parenting and family relationship changes since arrival in Canada), parenting supports needed and used by newcomer parents, and contributions of newcomer parents to other Canadian families. Results suggested parenting orientation and style depended on age/maturity of parents, the development stage of the child, size of family, child's/parent's personalities, culture, and religion. In relation to Canadian context, themes such as length of time in Canada, level of interaction with other Canadians, and presuppositions held to interpret culture around them were found to mediate the amount of time taken to adapt to Canadian society. Modifications in parenting styles depended on the length of time spent in Canada, level of education, speed of adaptation, amount of support received, economic/employment status, and strength of traditional values. (Anisef et al., 2001). In conclusion, the authors' findings support the idea that a reciprocal relationship occurs when newcomers enter a new context and the amount of positive support given to newcomers fosters a more rapid and smooth transition in adapting to the host culture (Anisef et al., 2001).

In her research on the four types of capital that immigrants possess, Kilbride (2000) suggested that community institutions and systems of the nation need to be acquainted with, develop, and improve the individual, social, and cultural capital of newcomer families and their children. In order to do so, Kilbride (2000) argued faculties of education must commit themselves to take on and respect the contributions of communities from all cultures, in an authentically collaborative manner. In order for this to occur, Kilbride (2000) suggested that 
support for the in-depth study of the diverse communities in the nation should be implemented and that a project of home language retention should be introduced into the education system.

Jose, C. Huntsinger, Huntsinger, and Liaw (2000) focused on how parental values are influenced by culture and whether time spent as a newcomer in a culturally different society would influence one's parenting practices. Results indicated Chinese parents appreciated traditional Chinese values and collectivist traits, exerted control over their child's environment, and emphasized academic achievement more than European American parents. In addition, Chinese American parents were more directive than, but equally as warm as European American parents. Finally, the researchers found that Chinese and Chinese American parents reported using more positive disciplinary techniques than the European American sample did. Interestingly, it was found that both Chinese samples endorsed individualistic traits (creativity, self-confidence and independence) just as much as the European American sample (Jose, Hustinger, Hustinger, \& Liaw, 2000).

In line with catering to the newcomer population in Canada, George, Tsang, Man and Da (2000) adopted a multi-method approach (focus groups and individual interviews) in their studies with eighty-two Mandarin speaking newcomers to assess the various needs and barriers faced by newcomers in Canada. Many participants experienced difficulties with linguistic and communication barriers, discrimination, familial conflict, isolation, and housing problems and problems obtaining employment,. Psychological adjustment was also problematic. Participants talked about how access and information about community and social services including English as a Second Language (ESL) classes, health care, subsidized childcare, services for seniors, and youth activities were limited. The participants suggested that in order to improve the services that were provided to newcomers, there should be more relevant programs to assist in the 
attainment of employment and recognition of their foreign credentials. ESL classes should cater to professionals and highly skilled newcomers, there should be more accessible information on community and social services, increased services in the Mandarin language, assistance in obtaining appropriate housing, and more programs that increase the participants' opportunities for cultural exchange between themselves and other Canadians (George, Tsang, Man, \& Da, 2000).

Lim and Weiling (2004) conducted a phenomenological study with ten immigrant Chinese-American women to understand how they negotiate differences in their values and perceptions of self in a new cultural context. The authors identified themes such as role as caretaker, identity, language, culture, and freedom of expression. One mother commented that the concept of filial piety was still important to her, especially in relation to harmonious living. Another participant commented that many non-Chinese or second-generation Chinese people misconstrue humbleness for low self-esteem. Some mothers had to switch behaviour in some situations because of cultural differences relating to the acceptance of compliments. Some mothers said they considered the priority of their family's needs over their own. Lastly, many women discussed the importance of education, closeness of familial relationships, frugality, financial prudence, ethics of hard work, quiet action, service to the community, and good morals (Lim and Weiling, 2004). Lim and Weiling's (2004) phenomenological study is important because it sheds light on the various themes and personal explanations of ten immigrant mothers from China. 


\section{Methodology}

An application for this study was submitted and approved by the Review Ethics

Committee Board at Ryerson University. During the process of this study several changes were made to the research protocol and each change was reported to, and approved by the REB at Ryerson University. First, the age range category of children was changed from birth to age three, to birth to age eight. This alteration was made because the focus of the study had shifted from attachment to parenting practices. Second, initially, I had intended to recruit ten participants for this study but due to time constraints, I had decided to recruit only five. Finally, the title of the study was changed from, Cross-Cultural Mothering Practices and Support from a Human Services Organization to Cross-Cultural Mothering Practices of Immigrant Chinese Women from Mainland China. The latter modification was made because the study narrowed its focus to cross-cultural mothering practices by excluding the aspect of Human Services organization in this study.

A qualitative approach was chosen for this study because by nature, qualitative inquiry seeks to understand a particular social situation, event, role, group, or interaction (Creswell, 2009). In addition, the nature of research design in qualitative methods incorporates flexible strategies in real world settings and utilizes methods to generate data which are flexible and sensitive to the participants' social context (Ritchie \& Lewis, 2003). Research settings are not manipulated or controlled as they are in experimental designs in quantitative research methods. Research methods in qualitative designs include observation, in-depth individual interviews, focus groups, biographical methods such as narratives, and analysis of documents and texts. The nature of analysis in qualitative studies focuses on the discovery of emergent categories, theories, and explanations relevant to the processes under investigation, while producing comprehensive 
descriptions which are based on, or offer an interpretation of, the perspectives of the participants in the particular social settings (Ritchie \& Lewis, 2003).

\section{Reliability and Validity in Qualitative Research}

In their study, Morse, Barrett, Mayan, Olson, and Spiers (2002) argued that there are five general verification strategies which can be applied to all types of research methods. The five verification principles are sufficient to all types of research because at heart they inculcate the necessary steps to ensure rigour in research and therefore meet the standards of a high degree of validity and reliability. The five verification strategies outlined by Morse et al. (2002) are: 1) methodical coherence, 2) appropriate sample, 3) collecting and analysing data concurrently, 4) thinking theoretically, and 5) theory development that moves between a micro perspective of the data and a macro conceptual/theoretical understanding.

The first verification strategy outlined by Morse et al. (2002), methodical coherence, refers to attaining a high degree of congruence between the research question and components of the specified method. Participants should be selected carefully and should represent or have knowledge about the topic of study. In addition, Morse et al. (2002) suggested that in order to attain reliability and validity, collecting and analysing data should be done concurrently. Thinking theoretically is another major aspect of the verification strategies which highlight the importance of focusing on the ideas that emerge from the data which should then be reconfirmed in new data. Finally, the process of theory development involves a move between a micro perspective of the data and a macro conceptual, theoretical understanding (Morse, Barrett, Mayan, Olson, \& Spiers, 2002).

Morse et al. (2002) argued that the process of verification in qualitative research is a continuous procedure of checking and confirming to ensure that the highest degree of rigour is 
incorporated to all research endeavours. Finally, Morse et al. (2002) suggested that in order to ensure rigour of research methods, the researcher should move back and forth between design and implementation to ensure congruence in the processes of question formulation, literature, recruitment, data collection strategies, and analysis. Overall, the five verification principles outlined by Morse et al. (2002) incorporate the necessary ingredients to all types of research because they focus on maintaining a high degree of rigour in every step and aspect of the research process.

\section{Research Design}

An Interpretative Phenomenological Analysis influenced by an idiographic and Heideggerian approach was used in this study. The idiographic nature in this approach puts the participant in a particular context by exploring his or her personal perspectives (Smith, Flowers \& Larkin, 2009). The Heideggerian ingredient commits itself to unlocking the information disguised in the participants' descriptions, evaluations, and narratives (Smith et al., 2009). The Interpretative Phenomenological Approach is inductive in nature and holds that participants are experts on their own experiences and can offer researchers understanding of their thoughts, commitments, and feelings through personal narratives (Reid, Flowers \& Larkin, 2005).

A phenomenological research approach was chosen for this study because it is an appropriate method of inquiry for understanding the complexities inherent in the negotiation of the values, beliefs, and perceptions relevant to the phenomenon of cultural aspects to mothering in a new cultural context (Lim \& Weiling, 2004). Furthermore, Javo et al. (2003) have successfully implemented this approach in a culturally contextualized manner with the objective of understanding how Sami parents in their sample experienced childrearing, and what their practices meant to them. Therefore, this method was deemed as appropriate for exploring how 
culture has shaped the values and beliefs which inform parenting practices and how mothers in this sample conceptualize their parenting practices in a new cultural context.

In order to ensure rigour in its method, the IPA approach outlines six steps in the analysis of data: 1) Reading and re-reading the data, 2) initial noting of descriptive and conceptual comments, 3) developing emergent themes, 4) searching for connections across emergent themes, 5) implementing the first four steps with each participant's data, and 6) looking for patterns across cases (Smith et al., 2009).The following section will utilize the five verification principles outlined by Morse et al. (2002) to display how the latter six steps are measures taken to ensure reliability and validity in IPA research.

Steps one and two of the six steps of the IPA approach to data analysis (Smith et al., 2009) coincide with the first verification principle (Morse et al., 2002), of ensuring methodical coherence. Through the process of reading and rereading participants' original transcripts (Smith et al., 2009), the investigator becomes familiar with the overall message in the participants' transcripts. By noting significant comments, such as ones which are descriptive and conceptual in nature (Smith et al., 2009), the investigator familiarises herself with the finer details relevant to the perceptions of the participants of a specified topic. In this manner, verification of methodical coherence (Morse et al., 2002) can be achieved because the investigator becomes increasingly familiar with participants' perceptions of a specified area of study, and therefore can continuously check to see if the data are congruent with the research question and method utilised.

With relation to verification principle two (appropriate sample) (Morse et al., 2002), Smith, Flowers, and Larkin (2009) highlighted the importance of recruiting a homogeneous sample (purposive sampling) for whom the research question will be significant. According to 
Smith et al. (2009) the choice of sample size depends on the degree of commitment to the case study level of analysis. Steps three to six of IPA analysis (Smith et al., 2009) coincide with verification principles three to five. By developing emerging themes from data, searching for connections amongst those themes, repeating this process with each participant's data, and then moving the analysis to the next level of searching for patterns across cases, the researcher must collect and analyse the data in a systematic fashion (Smith et al., 2009). In order to successfully connect and understand patterns that emerge from the data of the participants, the researcher must have the ability to relate and merge together themes in search for higher order, overarching superordinate themes.

Although IPA has outlined six steps to ensure a high degree of rigour in its data analysis, several weaknesses of this method should be noted. In her dissertation Foster (2009) discusses the notion that because IPA does not seek to find definitive answers it is not possible to make claims about the generalizability of results for the wider population of a specified group under study. In order to compensate for this weakness, first, I have expressly disavowed the possibility of generalizing from my data, and second, I have diligently adhered to the six steps of data analysis outlined by Smith et al. (2009) in order to focus on the method's strength, which is its ability to get the insider's perspective of a phenomenon.

An additional weakness of the IPA approach is that it has been criticised for not providing guidelines with relevance on how to incorporate the investigator's perspective without hindering participants' intended message of the specified phenomenon (Foster, 2009). In order to compensate for this second weakness, I have only used evidence directly from the original transcripts when introducing any new theme or a different perspective of a theme. 
Finally, a third weakness of the IPA approach as highlighted by Willig (2001) is that individuals might struggle to express themselves accurately which could block the subtleties of their experiences. To compensate for that weakness I incorporated follow-up questions during the interview sessions if any ambiguities were apparent in participants' explanations relevant to any issues discussed.

\section{Sample and Setting}

The sample selected for this study consisted of five first-generation immigrant mothers from Mainland China who were enrolled in an Ontario Early Years Centre (OEYC) which were located in densely populated areas in either Hamilton or Toronto, Ontario. The reason for this selection method is that IPA specifies that samples should be selected based on the principle of homogeneity (i.e., in purposive sample) (Smith et al., 2009). In my experience working at an OEYC and from talking to mothers during the recruitment process for this study, I learned that many mothers at the centre lived in the surrounding neighbourhood and were able to walk to the centre. As this study targeted immigrant mothers of young children, it seemed logical to go to a centre proving programs for mothers of young children.

Mothers were chosen who had lived in Canada for nine years or less. All mothers were between the ages of twenty and forty and had at least one child aged eight or under. Furthermore, these mothers were comfortable in spoken English and were able to read enough English to understand and sign the consent form.

Mothers rather than fathers were recruited because during the early years of their children's lives it had been noted that Chinese immigrant women tend to take a leading role in childrearing (Liu, 2009). A nine-year period was chosen because it is believed that mothers would still be shaping their cultural values and their parenting practices into their new cultural 
context (Su \& Costigan, 2009). Similar criteria were used by Su and Costigan (2009) in their study which focused on parenting practices and children's perceptions of their family's expectations of them. The authors recruited ninety-five immigrant Chinese families who had been living in Canada for nine years or less. Results indicated that children's perceptions of their family's expectations were significantly related to how they felt about their cultural heritage and ethnic identity. (Su \& Costigan, 2009).

I contacted five Ontario Early Years Centres (OEYC) that served a Chinese Canadian population and asked them to participate in this study. Two refused because they did not have a substantial number of Chinese participants at their centre. Another centre agreed to participate but I was not successful in recruiting from that centre due to low attendance rates. Two OEYC sites participated and each centre supervisor granted permission in writing. Both centres, one in Toronto and one in Hamilton, are in densely populated neighbourhoods. I travelled there and spent a total of five hours or more conversing with Chinese mothers at each centre. I joined one circle activity at each site with the parents and staff in order to gain the trust of the parents. Subsequent to this process, I approached mothers who seemed to fit the participant selection criteria and described the study to them. I did not directly ask mothers if they were willing to participate, but gave them the flyer (see Appendix A) describing the study and told them they were more than welcome to contact me if they would like to participate. Two mothers, one in Hamilton and one in Toronto, agreed to participate on the spot and scheduled the date and time of the meeting for the interview. Two acquaintances of the participants who were enrolled in the same OEYC sites contacted me to schedule an interview. I then verified that the participants fell under the required selection criteria and invited them to be interviewed. Three participants were interviewed at an OEYC site (two in Toronto and one in Hamilton) and two participants were 
interviewed in a public library in Hamilton. The two participants in Hamilton who were acquaintances had two or more children who were older than the children of the other two mothers in the study. In addition, one of these two mothers was the only mother who was employed at the time of the interview. The other two acquaintances from Toronto had younger children. The benefit to recruiting four mothers who were acquaintances (one pair of acquaintances from each of the two centres) was that homogeneity in sampling was increased because the mothers who were acquaintances had much in common with each other, but overall there were no significant differences among the five mothers, including the one recruited by a flyer. A twenty-dollar gift certificate for a local supermarket was offered to each mother who participated in the study.

\section{Data Collection}

Prior to starting the interview a consent form was presented to the mother for her consent to audio-record the interview and for sharing her words, not name, with the research community (see Appendix B for consent form). Mothers were told their identities would be kept confidential and that if they felt uncomfortable with any of the questions they could refrain from answering them. In addition, if any mother felt uncomfortable at any point in the interview she had the option to stop the interview.

Descriptive, evaluative and analytic, semi-structured interview questions were used (see Appendix $\mathrm{C}$ for interview questions) in each session and each interview lasted between an hour and an hour and a half. The nature of the questions was open, expansive, and non-leading in order to encourage mothers to fully describe how their cultural values and beliefs influenced the way they perceived parenthood. In some cases non-leading prompts were included if explanations were needed (e.g., "Can you tell me more about that?"). I ensured that my verbal 
input was kept to a minimum and the interviews moved from a descriptive to analytical, and finally to an evaluative tone. After each interview I reviewed the recordings twice, transcribed the data onto a word processing file, and listened to the recording again to search for errors in the transcription (Smith et al., 2009). This process enabled me to become familiar with the contents of the mothers' interviews.

A semi-structured interview approach was selected for this study to allow for flexibility in the presentation order of specific questions while providing a relaxed, open atmosphere for the participants to freely share information. An interview schedule was used as a guide to ensure the focus areas of the study were discussed with each participant (Smith et al., 2009).

In order to ensure the scientific rigour of data collection practices and increase validity, Yardly's (2000) principles for improving confidence in qualitative research were followed. First, I focused on issues surrounding sensitivity to cultural context by ensuring that mothers had sufficient time to express themselves if language barriers were evident. In addition, I reacted in a neutral yet friendly way to all of the mothers' comments, especially culturally relevant ones.

The second principle followed was commitment to a rigourous data collection process and analysis. This was done by demonstrating a high degree of attentiveness to the participants during and subsequent to the interviews. During the interviews, I attempted to display interest in mothers' narratives by making consistent eye contact with them throughout to ensure they felt they were being listened to, and to encourage their fullest participation. Subsequent to the interviews during the data analysis process, I stayed as close as possible to mothers' narratives to ensure that the originally intended message was portrayed correctly in the results section (Smith et al., 2009). 
The third principle I adhered to relates to data transparency and coherence in the presentation of the data. This was achieved by ensuring that each finding in the results section was clearly supported by mothers' actual words rather than my own personal assumptions (Smith et al., 2009).

Last, Yardly's (2000) fourth principle relates to making clear the impact and importance that a study has in general. This study seeks to inform its readers about the importance of culture relevant to the parenting practices. This study is important because immigration is prevalent across the globe and it is crucial that the receiving countries support and understand that culture plays a significant role in the manner in which people perceive their worlds and adapt to them. This study seeks to demonstrate that through the implementation of qualitative methods, richer descriptions relevant to immigrant mothers" perceptions about parenting in a new cultural context can be ascertained effectively.

\section{Data Analysis}

Data was analysed according to the six steps of interpretative phenomenological analysis outlined by Smith, Flowers, and Larkin (2009): 1) reading and re-reading the data, 2) initial noting of descriptive, linguistic, and conceptual comments, 3) developing emergent themes, 4) searching for connections across emergent themes, 5) implementing the first four steps with each participant's data, and 6) looking for patterns across cases. Themes were coded and the process was repeated across the whole data set.

In the first step of reading and re-reading, I listened to each mother's audio-recording while simultaneously reading the original transcript to ensure that each interview was transcribed correctly (Smith et al., 2009). This process allowed me to become increasingly familiar with 
mothers' narratives giving me the opportunity to retain the general message from each interview in my memory.

During the second step, descriptive, language use, and conceptual comments were noted and a process of deconstructing mothers' words to lift them out of context to better understand their meaning was implemented. Descriptive comments were noted for the purpose of reviewing and summarising each block of text of the mothers' answers using my own language. Comments relevant to language use were noted when mothers repeated certain words several times and used emotionally charged language. Conceptual comments were formulated by combining mothers' descriptive comments and language use, in the search for deeper meaning and overarching principles in their narratives (Smith et al., 2009). The process is described in more detail in the following paragraphs.

Two sheets of blank, coloured paper were stapled horizontally to each page, of each mothers' interview transcript. The first sheet, stapled to the right of the original transcript. was used to record both the descriptive comments and language use of the mothers. The second blank page, stapled to the right of the descriptive page, was divided vertically into two sections. The left hand column of the divided page was used to record conceptual comments. The right hand column was used to record emergent themes from the conceptual comments. Finally, these themes were grouped under several superordinate themes and numbered according to the order in which they appeared.

The third step of data analysis involved the development of emergent themes through the process of coding from the transcribed data, through the implementation of key words (e.g., study, or homework). 
The fourth step involved searching for connections among theme chunks across the data set of each mother's interview. This process involved identifying patterns, connections, and interrelationships among the key words in each mother's interview. Finally, I grouped similar key words together and labelled them under three superordinate themes (Smith et al., 2009).

Step five in the data analysis procedure incorporated repeating these four steps for each participant's interview transcript. Once all of the first four steps had been completed for all five transcripts, a careful review of the superordinate themes across the whole data set was applied (step 6). Those superordinate themes that repeated themselves several times throughout the data set were chosen as the superordinate themes of the study as a whole. 


\section{Results}

\section{Description of the Sample}

Five Chinese immigrant mothers originally from Mainland China participated in this study. Pseudonyms are used to protect the confidentiality of the participants. Background information is presented below in Tablel for each participant. Six mothers were interviewed during a five-week period but data from only five of those interviews were used. One mother preferred that the interview not be audio-recorded so I had taken notes manually throughout, but the data recorded was insufficient to analyse and include in this study. All mothers ranged in age from twenty to forty. Four of the five mothers emigrated directly from China to Canada from a mid- to large-sized city. One participant (Tamara) left China in 1999 and moved to Singapore, then to the United States, and finally to Canada. Furthermore, Tamara was the only mother who had received one of her degrees (masters degree) in Canada. The rest of the mothers completed their post secondary education in China.

\begin{tabular}{|l|l|l|l|l|}
\hline \multicolumn{5}{|c|}{ Table 1 } \\
\hline Participant & $\begin{array}{l}\text { Country of } \\
\text { Origin }\end{array}$ & $\begin{array}{l}\text { Level of } \\
\text { Education }\end{array}$ & $\begin{array}{l}\text { Arrived in } \\
\text { Canada }\end{array}$ & $\begin{array}{l}\text { Age \& Sex of } \\
\text { Children }\end{array}$ \\
\hline Nina & China & Teacher's College 2007 & $\begin{array}{l}1 \text { yr. Girl } \\
7 \text { yrs. Girl }\end{array}$ \\
\hline Linda & China & $\begin{array}{l}\text { Bachelor's } \\
\text { Degree }\end{array}$ & 2009 & $\begin{array}{l}3 \text { yrs. Girl } \\
\text { Jessica }\end{array}$ \\
& China & College Diploma & 2006 & $\begin{array}{l}7 \text { yrs. Boy } \\
5 \text { yrs. Boy } \\
6 \text { mos. Girl }\end{array}$ \\
\hline Tamara & China & Master's Degree & 2003 & $\begin{array}{l}8 \text { yrs. Girl } \\
5 \text { yrs. Boy }\end{array}$ \\
\hline Rachel & China & $\begin{array}{l}\text { Bachelor's } \\
\text { Degree }\end{array}$ & 2003 & yrs. Girl \\
\hline
\end{tabular}


Additional background information related to the participants and their spouses is presented in Table 2. All the participants had active careers in China. All but four participants (Tamara) became homemakers in Canada. All but one of the participants' husbands were employed in Canada. All but one of the participants (Rachel) completed their postsecondary education in China. Rachel's husband had completed his postsecondary education in Canada where he had been living for over ten years. 


\begin{tabular}{|c|c|c|c|c|}
\hline \multicolumn{5}{|c|}{$\begin{array}{c}\text { Table } 2 \\
\text { Backgrounds of the Chinese Mothers and their Spouses }\end{array}$} \\
\hline Participant & Job in China & Job in Canada & $\begin{array}{l}\text { Husband's } \\
\text { Education }\end{array}$ & $\begin{array}{l}\text { Husband's Job } \\
\text { in Canada }\end{array}$ \\
\hline Nina & $\begin{array}{l}\text { High School } \\
\text { Teacher }\end{array}$ & Homemaker & $\begin{array}{l}\text { Bachelor's } \\
\text { Degree }\end{array}$ & $\begin{array}{l}\text { Computer } \\
\text { Technician }\end{array}$ \\
\hline Linda & Marketing & Homemaker & Masters Degree & Unemployed \\
\hline Jessica & Accounting & Homemaker & Doctoral Degree & $\begin{array}{l}\text { Mechanical } \\
\text { Engineer }\end{array}$ \\
\hline Tamara & $\begin{array}{l}\text { Researcher at a } \\
\text { University }\end{array}$ & Contract Engineer & Doctoral Degree & Faculty Member \\
\hline Rachel & $\begin{array}{l}\text { Marketing } \\
\text { Manager }\end{array}$ & Homemaker & $\begin{array}{l}\text { Bachelor's } \\
\text { Degree }\end{array}$ & $\begin{array}{l}\text { Software } \\
\text { Development }\end{array}$ \\
\hline
\end{tabular}

The objective of this study was to explore immigrant mothers' perceptions about how their culture shaped their values and beliefs relevant to their parenting practices. In addition, the second objective of this study was to discover how mothers conceptualized their parenting values and beliefs in their new cultural context. Following in-depth individual and group-level analyses, three significant themes emerged: 1) behaviour modelling, 2) education, and 3) discipline.

\section{Behaviour Modelling}

Three of the five participants discussed the importance of modelling positive behaviour for their children. They emphasised the notion that parents should be consistent in their behaviour in every context, not only when they are in front of their children. Most mothers recognized that children were always observing and imitating others, especially their parents. In addition, mothers identified the significance of displaying behaviours that were in congruence with the behaviours that they wished their children acquired. Two subthemes under behaviour modelling were identified: 1) modelling and habit formation, and 2) modelling and mutual respect. 


\section{Modelling and Habit Formation.}

Two mothers described the significance of modelling in relation to habit formation in their children. They recognized the idea that habit formation was a gradual process and children acquired habits from a very early age. In addition, they were aware of the concept that if parents wanted their children to acquire positive habits then they themselves needed to first model an array of positive habits. One mother used the example of how television watching can hinder a child's future concentration, especially in relation to education.

Just one thing: I told her to reduce the time to watch...television because you know, some people think when the children spend more time to watch television he or she cannot concentration on their learning study later. You know, when he grows up they cannot... focus on their study. How, I think the is very important to make the behave, behave the whatever home or outside you know, parents are the model for the our children. We should continue the I mean the same behaviour whatever outside or at home. So, whatever our children can follow me, you know, what you are and your children will be. So I mean, what do you want your children what to do, and you should do, you know. Ya, model for our children. So if you hope your children have a good behave then you should have a good behaviour first. For example, you hope your children love to study, so when you are at home you should not watch television and you should not spend much time to watch television. You should reading, building a good model for our children. (Linda)

\section{Modelling and Mutual Respect.}

One mother said mutual respect between mothers and children was acquired through modelling a parent's respectful behaviour prior to a child's ability to demonstrate respectful behaviour. Children come to understand, internalize, and imitate respectful behaviour towards others. She used an example of her own struggles in remaining calm and collected when addressing certain issues with her children. She blamed her past and present health issues on any angry emotional outbursts towards her children.

I think like very parents need to behave like respect kids. You know, you can say anytime maybe you angry it's scared, if you know like if you everyday happy give a kiss not too much stress not a scared a lot of be quiet. You know like some 


\section{Education}

time, like me I am very angry like I have thyroid. I tell kids to be quiet, they know I am very angry. After I am happy, they talk you know she told me mommy I like you happy like that. I think it's very important if you do it good to kids, they say they can learn like that. It's very important but parents is very hard life is very hard. So ya, I think for everybody opinion different. You know, for me I think very important like you do good way, like something respect somebody, they kids maybe he learn like that. If not respect, maybe learn is the better way you know. I think very important.(Jessica)

It was evident that for four of the five participants their cultural backgrounds influenced their perceived importance of education. Four mothers described how Chinese parents, in China, believed that the one and only duty of their child was to study to become financially successful. Participants felt children in China experience significant pressure to excel academically in comparison to Canadian children. Most mothers talked about how children in China had little time for anything but schoolwork. They believed that Chinese children were unhappy because they dealt with a great deal of pressure because of the amount of studying and homework. Some participants believed that Chinese children in China also suffered due to lack of engagement in extracurricular activities. Mothers thought that education was one of the most important things for their children's future success. They also thought that it was important to educate their $\therefore$ children mainly in mathematics and language. These four mothers, irrelevant of their children's ages, expected their children to study more than they had to at school. In addition, some believed that education should be fun and presented in a more relaxed manner. One mother, comparing China and Canada in education, thought the immense competition in China led parents to focus on children's education in an imbalanced manner. She talked about how Canada was much more relaxed, competition for jobs was not as great, and therefore children were not as pressured to study all the time.

I think in China and Canada a big different. In China, children always study very hard and the parents, most of the parents think the children only need their duty 
only study, study every day from morning to evening. You know we have about 7 o'clock and maybe have to go to bed maybe 11 o'clock. The whole day they study. Morning go to school and after they do the homework, and afternoon go to school, and afternoon do their homework, and maybe go to bed. Very hard most of the Chinese children like this. So I think my daughter came to Canada I think it's very my parents say, my daughter very luck, you don't need to do homework all day. So in China the parent always think the children's duty is study very hard study. Ya, it's different country and different situation we have to do like this. If they can't go to the university, they can't get a good job, they can't have a best life. You know, it's relaxed here, you don't need to go to university you can go to college, even not college, and you can have a relaxed life it's different. So Chinese kids such hard work every day. (Nina)

Although Nina believed that children in China studied too much, she also believed that education was of the utmost importance to her children's futures. But she believed it was also important to eliminate the pressures that went along with it and to present educational tasks in a more pleasant and relaxed manner.

Always after school, she come back home, I go to pick up her. If the weather is good I let her play outside about 1 hours and then come back home. Every day the most important things in my older daughter, I need to help her study more things. You know, in China the students always study very hard, so in here I try to let my daughter learn more things than they study at school. I teach her Chinese every day one words or two words and also they need write some diary in English, not as part of school just a diary. Whatever she write, she always write diary about her website game. I ask her can you write anything else. Some mathematical exercises like this. After her study she can do whatever she wants to do. Play game, or read book, or just play with her baby sister. So, I think during these things, I am take care emotional, how you say emotional, because during the study I don't want to let her feel it's a hard work, study it's a boring things. I try to let her feel this is necessary, just like I let her learn some Chinese words it's a very important, ya, and math exercises. I try to find some work on the website. It's like a game, it's not hard and this is a different and during these things we can talk to each other just talk about when you write something like this. (Nina)

One mother talked about making sure that her daughter learned to read Mandarin characters. She introduced character cards to her at the early age of two to make sure she not only spoke her 
home language but read it as well. Her two-year-old daughter was able to recognize almost two

hundred Mandarin character cards. The following quote is illustrative:

In house I speak Mandarin with my daughter and with the card, the word card, I write in Chinese and show the baby how to pronouncing and it the baby knows about the word. I want the baby in the future she can understand the Chinese word, the Chinese history. I think maybe in Canada have some Chinese children she just can hear or can speak Mandarin or Chinese but she can't read or writing. I want to let my daughter is knows about some Chinese histories. Sometimes I read the book for the baby, card, and then my daughter almost knows the Chinese word almost two hundred Chinese word and now she just two years and three months but she can speak the whole sentence and she can understand you everything and she can explain her. (Rachel)

\section{Discipline}

Two mothers talked about their frustrations because of their lack of ability to get their children to comply with their wishes in daily routines such as eating, going to sleep on time, and studying. Two mothers talked about the differences in disciplining techniques between Canada and China. They thought that it was socially unacceptable for parents to use physical force towards their children in Canada and felt that they lacked control over their children because of this cultural gap. One mother thought that the Canadian government believed that parents should allow their children to do as they wished. She constantly told her children that in China, children were not allowed to do whatever they wanted, and that they must study their home language. She reminded her children that they were Chinese and that they must live up to Chinese cultural expectations. She discussed how she tried not to use physical force to get them to comply with her wishes. She talked about punishing her children and then telling them why they needed to be punished and that she loved them.

Here you know, in China and in Canada, it is different and Canada government say you can't hit the children. You can't operate to them to do something. Just let him do what they do and China it is totally difference. People think that you need much more study, study, study. So just you know, sometimes I say you need to study because you are Chinese. I don't want you to grow up to speak English to 
Mommy. I want you study Chinese so every day. My children are good but sometimes have not a good listening. Children you know just like I will try I don't want to hit you, but sometimes I punishment you because I love you. I don't want, I don't hit. Sometimes you say I hit them a little bit but I just want you to know Mommy love you and want you to be good. I want you to be good just this morning not to be late to the school. Just a sleeping, I want you sleeping in time I don't want you delay and then you lack of sleeping and you will get sick. I want you eat food you too much skinny, I want you big. I don't you be sick, so I just told them. (Tamara)

Another mother said she always had to ask her children to do something several times before they complied with her wishes, which made her sad. She claimed that her older son behaved much better outside the home than inside, and she wished that he would behave well in all contexts. She wanted someone to give her advice about how she could discipline her children so that they listened to her. She sought advice from a public nurse and other mothers in the past. She had attempted to implement the time-out technique with her children as outlined by one mother.

I think it's like parents is hard, I think my kids is very hard for me. A lot of times I talk to them many times, they not listen to me. I feel very sad, I think my life is hard like that. Sometimes like for example, before they want to go to school they didn't eat the breakfast. I ask them three times, five times. I feel very sad. Sometimes they are no eat, sometimes they job, and sometimes they play with themselves. I think parents is very hard. I think all is behave but only at home not behave. Like my older one, he go to school and like teacher give some, like some congratulation. You a good baby, like good job. I said Peter, could you listen, could you eat your dinner. I want, like sometimes I told them something they, if I want to talk one time so they do. Peter could you eat breakfast? I am very happy, you know but sometimes they are very slowly they didn't do anything. A lot of behaviour like that, I am feel very sad. So I want someone to tell me, give me advice how to give the best behaviour. I don't know but I ask a public nurse, I ask her some kids, every kids different tell me like that. Most not behave because most I always ask somebody parents my kids giving me trouble most of the time but they say most of the parents tell me, me too, me too. You know, sometimes my friend, you know if they not behave you can out in the chair, maybe one is one minute, maybe five is five minute, maybe the older one seven minutes, like that. Sometimes I do like that so I think, I tell a lot of parents the same like me, idea you know. (Jessica) 


\section{Discussion}

This study investigated how the cultural values and beliefs of immigrant Chinese mothers from Mainland China shaped their parenting practices. The subsidiary question of this study focused on how mothers conceptualized and negotiated their parenting practices in a new cultural context, in Canada.

Three out of the five mothers shared their ideas about the importance of modelling positive behaviours towards their children. Modelling positive behaviours was divided into two subthemes: 1) modelling and habit formation, and 2) modelling and mutual respect. Through the investigation, it became evident that culture played a significant role in four mothers' perceptions about the importance of education, for their children's future success. Finally, two mothers talked about their struggles in disciplining their children. They thought that it was socially unacceptable to use physical force towards their children in Canada and felt that they lacked control over her children because of this cultural gap, namely in getting their children to comply with their wishes in daily routines and studying.

\section{Behaviour Modelling}

Three of five mothers talked about the importance of being consistent in modelling positive behaviours towards their children because they were aware that children were always observing and imitating other people. These three mothers were also aware that they should model behaviours that were in congruence with the behaviours that they wished their children acquired. Behaviour modelling was emphasized in relation to habit formation and mutual respect.

The finding that three of the five mothers endorsed modelling strategies in their parental behaviours was inconsistent with Cheah and Rubin's (2003) findings that Chinese parenting 
styles and practices endorsed more directive, and less active orientated modelling strategies. In their study, Cheah and Rubin (2003) hypothesized and found support for the conception that European-American mothers provided a greater proportion of modelling strategies in their parenting practices than their Chinese counterparts. In contrast, they said, Chinese mothers endorsed higher proportions of training and education in their parenting practices. The hypotheses that Cheah and Rubin (2003) outlined were based on the assumptions that "Western" parents exemplified behaviours that were in congruence with the idea that children learned better through observation than through direct instruction. In contrast, the authors suggested that Chinese parents were highly concerned with their children's proper conduct and therefore endorsed what the authors called "training" and "education" to ensure that children complied with the desired socialization goals (Cheah \& Rubin, 2003). One reason for the discrepancies in the findings may be that Cheah and Rubin's (2003) sample of Chinese mothers lived in China, and the choice to come to a different country and accept new ways of parenting can signify that mothers in this study are more flexible to acquiring different parenting strategies and techniques than mothers who have not lived outside of China.

The authors referenced Chao (1994) to support their assumption that Mainland Chinese mothers still supported the use of training as a means of socializing their children. One major point that they failed to mention was that Chao (1994) did not conceptualize "training" in the same way that Cheah and Rubin (2003) did. Cheah and Rubin (2003) categorized training as a parenting practice that was authoritarian in nature. In contrast, Chao (1994) asserted that the concept of "training" a child according to Chinese culture had no relevance to authoritarian parenting practices. In addition, it was not a military style of parenting as perceived as such by many Westerner parents. In contrast to the cold nature of military training, Chinese parental 
styles incorporate high levels of involvement, care, concern, and physical closeness that are prevalent in most Chinese families (Chao, 1994).

In line with Chuang and Su's (2009b) finding that Chinese Canadian parents balanced their parenting practices with their children's needs, so too did the sample of mothers in this study. This balance was evident in the manner in which one mother highlighted the importance of ensuring that her children felt respected and safe around their mother even during times when she disciplined them. In addition, the three mothers in the sample that discussed the importance of behaviour modelling did not, in their narratives, fit the description of authoritarian mothers. Similar to the mothers in G. Liu and Gao's (2010) sample, these three mothers found a balance between their authority and their flexible child rearing practices. This balance was evident in the means through which they discussed and applied parenting practices, via behaviour modelling techniques. The relationship between mothers and their children were not unidirectional, rather mothers made sacrifices to ensure that they practiced what they preached, and modelled positive behaviours towards their children. The latter statement was exemplified through one mother's description of how, if parents wanted their children to love to study, then they themselves should display adult behaviours relevant to knowledge acquisition, such as reading. She mentioned that parents should avoid the temptation of watching television, or spending too much time on the computer in order to model correct behaviours rather than just controlling their children's activities. According to the three mothers' beliefs, parents must actively model correct and healthy behaviours. These parenting practices did not fit Baumrind's (1978) description of authoritarian parents, who are more directive and controlling and attempt to reduce and eliminate their children's autonomy. 
Chuang and $\mathrm{Su}(2009 \mathrm{a})$ suggested that the difference they witnessed in relation to the previous assumption that low power strategies correlate with high positive comments may point to cultural differences. Specifically, modesty is an important virtue in Chinese culture and it may be that Chinese mothers who respect this cultural prescription do not overtly display their pride in their children through positive comments in the presence of others. It is possible that this display of pride may be exhibited towards children in private contexts or in other ways.

It is interesting to note that most of the research on Chinese parenting styles is based on Baumrind's (1978) typology of parenting styles, which attempt to categorize Chinese mothers in one of the three parenting styles of authoritarian, authoritative, and permissive parenting styles. Although Baumrind (1978) herself stated the three parenting styles were only relevant to the orientations of parents who were raised in "Western" cultures, many researchers still apply the aforementioned parenting constructs to the study of Chinese parenting styles. Taken together, the finding that three Chinese mothers endorsed behaviour modelling in their parenting practices, and the inconsistent findings in the literature related to Chinese parents' parenting styles, suggest that more culturally contextualized research such as Bernhard (1995) recommended must be implemented in cross-cultural research on parenting styles and orientations of Chinese mothers.

\section{Education}

Four of the five participants in this study discussed the importance of education and related it to their children's future success in adulthood. The relationship between culture and education was apparent in four mothers' descriptions about how Chinese parents in China believed that the one and only duty of their children was to study and become financially successful in adulthood, and how they themselves wished for their children's success through academic achievement. All four mothers provided extracurricular learning activities and 
homework assistance for their children from an early age (i.e., preschool). Mothers placed special educational emphasis on the learning and maintenance of the Mandarin language and mathematics.

The finding that four of the five mothers strongly emphasized educational achievement for their children is consistent with findings from other studies done with Chinese samples (Jose, et al., 2000; Lin \& Fu, 1990). Lin and Fu's (1990) study of Chinese, immigrant Chinese, and Caucasian-American mothers, based on constructs such as parental control, encouragement of independence, and emphasis on achievement, found that Chinese mothers, whether living in China or not, emphasized academic achievement in their children significantly more than the Caucasian American sample (1990). Jose et al. (2000) found similar results, irrespective of the amount of time the mothers spent as immigrants.

These studies support my findings that Chinese mothers tend to value education and their immigration status does not significantly change this cultural value. Two out of the four Chinese mothers, however, discussed the importance of removing the stress of studying by presenting material in a more relaxed and pleasant manner. The mothers realized that competition for jobs in Canada was not as great as in China and were able to relax and present the learning materials to their children in a more pleasant manner.

\section{Discipline}

Two mothers talked about their frustrations with their children's resistant behaviour to activities such as eating, going to sleep on time, and studying. They were under the erroneous impression that it was illegal to hit or spank children in Canada and found it difficult to successfully implement other disciplinary techniques. They did not believe in endorsing physical punishment as a means in disciplining their children, but they felt frustrated that their children 
did not comply with their wishes and sometimes lost their tempers with their children. After losing her temper and yelling at her children, one mother described how she talked to them about why she became irate, what she expected of them, and that she loved them and only wanted the best for them. One mother said a mother she met at an Ontario Early Years Centre had given her advice about the time-out technique. The mother in the study had also sought advice from a public health nurse about the ways in which she could implement disciplinary techniques that were effective with her two sons.

In a similar vein, Ali (2008) found that some of the parents in her sample were also frustrated about issues surrounding discipline. One main finding was that many parents felt a loss of their own parenting self-efficacy and one participant related this feeling to her lack of ability in effectively disciplining her son as she feared that he would call the authorities as he had before.

The two mothers in this study felt frustrated because they did not believe in harsh punishment, but seemed to lack knowledge about different means of disciplining their children. It seemed as though they wanted to get some more advice and guidance.

The qualitative method for gaining information into the participants' worlds shed light on the issues surrounding disciplining techniques from a cultural perspective (Rogoff, 2003). Had mothers simply filled out questionnaires about the means that they used in disciplining their children, it would not have become apparent how mothers' past cultural experiences have shaped the way they view the issue (Javo et al., 2003). Furthermore, simple and quantifiable (Ratner \& Hui, 2003) responses from the mothers would not have elicited information about how their new cultural context did not support their old cultural contexts relevant to disciplining techniques. This dissonance motivated mothers to re-evaluate their cultural understandings of the issue and 
caused frustration but at the same time motivated mothers to seek out information about other techniques.

The Interpretative Phenomenological Analysis approach that was applied contributed to this study in several ways. First, in allowing the researcher to explore the essence of human experience of a particular phenomenon (Smith et al., 2009), I was able to delve into the worlds of each of my participants with relevance to how their culture has shaped the way they perceive their roles as caregivers in a new cultural context. By providing flexibility in relation to the types of questions asked (open and expansive) and time allotted to answer those questions, I was able to have a deeper understanding of my participants' worldviews from various angles. These angles included the perspectives of the participants as mothers, children, and sisters in relation to other people. These various angles explored added a more holistic and personal touch to this study. In addition, the flexibility inherent in this method provided a new and differing perspective (Smith et al., 2009) about cross-cultural mothering practices of Chinese-Canadian immigrant women in relation to the techniques that mothers applied in their parenting practices such as behaviour modeling.

The various steps taken to compensate for the weaknesses of IPA research mentioned in the methods section were compensated for through the measures taken throughout the process of research. First, the inability of the researcher to generalise findings to a wider population of the specified group under study (Foster, 2009), was balanced by focusing on the method's strength of having access to an insider's perspective (Smith et al., 2009) of how mothering practices were influenced in the new cultural context. Mothers seemed comfortable to share their perspectives on parenting and the various dilemmas that they faced in disciplining their children. The second weakness discussed of the IPA method was its lack of guidelines on how to incorporate the 
investigator's perspective without hindering the participants' intended messages (Foster, 2009). The precautions that were taken to compensate for the aforementioned weakness that involved presenting direct evidence for each theme and new perspective seemed successful, in that it ensured continuous transparency of the data. Finally, the follow up questions that were implemented in situations where mothers struggled to express themselves were helpful in overcoming communicative hurdles and helped clarify any ambiguities in mothers' narratives.

\section{Limitations and Recommendations for Future Research}

Several limitations in this study should be noted. The first is that all of the mothers in this study had completed post-secondary education. Future studies are needed to explore parenting practices and values across a more demographically diverse sample of immigrant mothers from Mainland China. In addition this study incorporated a small sample of only five mothers and future studies should include larger samples. This study was initially going to include ten participants, but due to time constraints only five participants were recruited. Furthermore, after recruiting the third participant I contacted the review ethics board at Ryerson University to change the defined age of children from aged three and under to aged eight and under. This change was made because the focus of this study had shifted from attachment to parenting practices. This research study also focused on only one cultural group. Future research should include several cultural groups. An additional limitation is that this study did not include literature outside English language databases. Future research focusing on the Chinese population should include recent literature in one or more of the official languages in China. In addition, literature that implements qualitative research methods to the study of cross-cultural mothering practices is limited. Future research endeavours should implement qualitative research methods in the study of cross-cultural mothering practices for the purpose of ascertaining rich 
descriptions of the phenomenon. Finally, I must note that I am not Chinese. This can be perceived as a benefit in some cases. Being an outsider to my participants' culture may have made them feel less restraint in expressing sensitive issues, especially if they were aware that cultural nuances prevalent in Chinese culture were not part of other cultural groups.

\section{Conclusion}

The main goal of this study was to explore how the values and beliefs of immigrant mothers from Mainland China have shaped their parenting practices. A subsidiary purpose was to ascertain information about how mothers negotiated parenting in their new cultural contexts. Finally, a qualitative research method was applied in this study for the purpose of extrapolating rich descriptions relevant to how culture shapes parenting practices.

The main goal was achieved in that the construct of culture was evident in two themes, education and discipline. It was clear the value that mothers placed on education was influenced by the cultural values they had brought with them from Mainland China. Many references to China were made during conversations about the value of education. Furthermore, the issue of discipline was apparent in two of the five mothers' descriptions and it was clear that mothers were in the process of renegotiating and educating themselves about disciplining techniques The finding that three out of the five mothers incorporated behaviour modelling in their parenting techniques was interesting because a large amount of research on Chinese parenting styles classifies Chinese mothers' parenting styles as more authoritarian in nature. Finally, the phenomenological, qualitative research method that was applied in this study gave space for the voices of the participants, and consequently made possible the rich descriptions that informed the subject area of culture and parenting practices. 
The findings from this study can be useful to people who work in the field of Early Childhood Education because they address issues that most parents face in their childrearing practices with insights specific to parents of Chinese heritage. The finding that ChineseCanadian mothers used behaviour modelling in their parenting practices helps educators understand that other cultures develop their parenting techniques using principles that lead to outcomes that are desired by many cultures. This information can assist educators in feeling more comfortable connecting with mothers from other cultures and the children they care for. Stronger relationships between parents and educators can support immigrant parents in becoming acquainted with various disciplining techniques, aiding parents to adapt their parenting techniques in a new cultural context. In addition, this study contributes to the field of Early Childhood Studies in that it builds the foundation for more precise research in the future by highlighting the various discrepancies that exist in the literature on Chinese parenting styles.

Based on the finding that Canadian-Chinese mothers incorporate behaviour modelling in their parenting practices, future research should focus on expanding constructs beyond typically used ones such as Baumrind's (1978) typology of parenting styles or autonomous versus connectedness orientated parenting styles, to behaviour modelling techniques. Based on the findings that education is culturally influenced, future research should focus on how other cultures promote academic achievement in their children so that other ways of educating our youth can be explored for the purpose of enriching the local education system.

As mentioned earlier, quantitative research methods have been applied for most of the research on cross-cultural parenting practices. It is crucial to conduct more qualitative research on cross-cultural parenting practices because, in order to find out how a construct is perceived in a specific culture, in-depth qualitative research and analysis relevant to the construct must be 
determined first. Once deeper meanings of the specific construct have been explored, the results and implications formulated from cross-cultural research can be made more culturally relevant and therefore more meaningful.

Future research with Chinese-Canadian immigrant families should incorporate fathers as well. It is important to obtain information about how fathers reconceptualise their roles in the new cultural context. By including fathers in the study of Chinese-Canadian immigrant families, a more holistic picture can be formulated with reference to how the family as a unit works together and is affected by the new cultural context. In addition, if I were to conduct a similar study in the future, I would include a more demographically diverse comparison group of Chinese-Canadian immigrant mothers to check whether the specific demographic characteristics of my sample (i.e. attainment of higher education) had any bearing on the results of this study. Finally, I would include a group of newcomer Chinese mothers (5 years or less) and compare them to Chinese-Canadian mothers who have been living in Canada between five to ten years to measure the type of differences that exist in relation to how mothers conceptualise their .parenting practices in the Canadian context.

Throughout the process of this study, I have acquired several useful skills that have contributed to my professional growth. First, I have widened the scope of my knowledge of research methods and learned how to conduct an Interpretative Phenomenological Analysis study. This has given me the ability to expand my skills as a researcher which can be applied to knowledge acquisition in general. Additionally, I have developed more effective interviewing skills that have assisted me in understanding the importance of actively listening to and appreciating people's life stories. 


\section{Appendix A}

Flyer

I would like to invite you to take part in an interview. I am a graduate student, in the Early Childhood Studies Program at Ryerson University and I am interested in learning more about how your culture, ideas, country of birth and family have influenced the way you teach and play with your children. I would like to Interview first generation newcomer mothers from Mainland China. At least one of the participant's children should be under the age of three. Because I do not speak Mandarin/Cantonese mothers should be comfortable communicating and reading in English. The interview will last for about an hour/hour and a half, and will take place in a quiet room in the centre. With your permission, I will tape the interview but I will not use your real name for anything that I share with others (you do not have to give me your real name although you must sign and print your name on a consent form to be in the study). I will use the words you give me but not your name. If you choose, other family members may be present during the interview but children must be supervised by another adult so that you can speak freely without interruptions. To show my appreciation I will be giving a \$20 gift certificate (local supermarket) for those who participate. The choice of participation will have no impact on your future relations with the Ontario Early Years Centre or with Ryerson University. The staff at the Ontario Early Years Centre will not know who participated in this research project and therefore will not have access to any names of the mothers who were interviewed.

My name is Michelle Baron Phone number: 905-973-9603 (Hamilton number) Email: michal.baron@ryerson.ca Thank you! 


\section{Appendix B \\ Ryerson University \\ Consent Agreement}

Title of Study: Cross-Cultural Mothering Practices and Support from a Human Services Organization.You are being asked to participate in a research study. Before you give your consent to be a volunteer, it is important that you read the following information and ask as many questions as necessary to be sure you understand what you will be asked to do.

Investigators: The main investigator is Michelle Baron from Ryerson University. Michelle has a Bachelor's degree in Psychology and is currently in the Masters of Early Childhood Studies Program at Ryerson University, in the Community and Social Services Department. Michelle's supervisor is Dr. Judith K. Bernhard.

Purpose of the Study: The purpose of this study is to better understand how cultural beliefs and values influence the way mothers like you from Chinese backgrounds, experience motherhood. In addition, this study also examines how mothers like you feel about the type of support you get from the centre, mainly on a cultural level. A total of ten mothers will be asked to join this study. Mothers will be first generation newcomers to Canada, have a child aged 3 and under, are between the ages of 20-40, and should be comfortable in speaking and reading English.

Description of the Study: Once you have agreed to participate we will set up the date and time that is most convenient for you to come to the centre or in your home (whichever you prefer). If you would like to meet at the centre, then you and I will go to a quiet room and I will ask for you to sign and print your name at the end of this consent form so that $I$ can audio-record your words. If you would like me to come to your home then we must have a quiet place to sit and talk so that I can concentrate on everything that you have to say. I will not use your real name in my paper and I will not give your personal contact information to anyone, not even my university. I will however use your words in my paper but not your name.

The interview will take anywhere between an hour to an hour and a half and we will meet once. The interview will take place wherever the participant feels most comfortable as long as the location is quiet and children are supervised by others (examples: In the home of the participant, in a quiet room at the Ontario Early Years Centre or at a library, etc.) I will ask you questions about your experiences as a mother, about your cultural beliefs and about your general experiences at the centre that you are enrolled in. I will ask you about fifteen questions and sometimes I might ask you to tell me more about something, so that I can understand your answer better.

What is Experimental in this Study: None of the procedures used in this study are experimental in nature. The only experimental aspect of this study is the gathering of information for the purpose of analysis through an interview.

Risks or Discomforts: A few of the questions in this study may seem personal and surround sensitive issues. For example, I will ask you a question about the relationship you had/have with your parents. If you feel uncomfortable, and do not want to answer this question than we can skip it and move on to the next question and or come back to it later. In addition, I will ask you to describe the structure of your home when your child was brought into it, after he/she was born. If this question makes you uncomfortable then feel free to tell me and we can skip it and if you feel comfortable to come back to it later on in the interview than we can do so, if not, than we can leave it out. Last, I will ask you about your general experiences at the centre that you are enrolled in. Once again, if you feel uncomfortable to answer any aspects of the question feel free to skip it and or come back to it later on in the interview. 
If you feel upset or uncomfortable at any point in the interview then we can take a break or totally end the interview.

Benefits of the Study: I cannot guarantee, however, that you will receive any benefits from participating in this study at the centre but you might feel as though you have made your voice heard about the ways that you choose to parent and the ways that your cultural and personal beliefs have shaped the way you parent. The study will be shared with the centre, so if there are any suggestions that you have about the centre's support of your mothering practices, then they will be able to read about them and decide if they want to change the way they implement their programs (your real name will not be mentioned in the study).

The study will also have benefits for society, in two ways. The first, human services organizations will better understand how culture influences the way people choose to parent. They will also understand that the way mothers choose to parent is influenced by the way that a mother was raised which includes her own personal, familial and cultural beliefs. Second, people who read this study may start to ask questions about how others do things instead of just going along with the way that things have been done in the past.

Confidentiality: Confidentiality will be maintained to the extent allowed by law, five years. Confidentiality will be maintained and the audio-recordings will be stored in a locked file, in the researcher's home for five years. The audio-recordings (transferred onto a removable disc) and consent forms will be kept in separate locked files. Numbers (not names) will be assigned to each digitized interview recording. Recordings may be shared with other researchers in the community but no identifying information will be given of the recording. The recording will be erased off of the removable disc and laptop after five years. The recordings will be transcribed onto paper after each interview.

The recordings will be used for the purpose of this study (Masters research paper) and possibly for publication in a peer reviewed journal. Your words not name will be used to analyze how your culture and personal beliefs influence the way you raise your child. Also, your general comments about the centre and how they support your mothering practices will also be analyzed according to your words. If you choose to change any of your statements feel free to contact me and we will change and or omit any information via e-mail, by phone or in person.

Incentives to Participate: A twenty dollar gift certificate will be given to mothers who sign consent to audio-record the interview and who complete the interview until the end. If the participant chooses to stop the interview in the middle than ten dollars worth for a gift certificate will be given. The gift certificates will be given at the completion of the interview. If the participant comes to meet the researcher and then after reading this consent form, decides not to participate then no incentive will be given.

Costs and/or Compensation for Participation: The only cost to the participant will be the transportation to and from the centre, which will be paid by the participant.

Voluntary Nature of Participation: Participation in this study is voluntary. Your choice of whether or not to participate will not influence your future relations with Ryerson University. If you decide to participate, you are free to withdraw your consent and to stop your participation at any time without penalty or loss of benefits to which you are allowed.

At any particular point in the study, you may refuse to answer any particular question or stop participation altogether. In addition, if you choose to participate in this research project, your participation will have no impact on future relations with the Ontario Early Years Centre or Ryerson University. 
Questions about the Study: If you have any questions about the research now, please ask. If you have questions later about the research, you may contact.

$$
\begin{gathered}
\text { Michelle Baron } \\
\text { (905)-973-9603 } \\
\text { michal.baron@ryerson.ca } \\
\hline
\end{gathered}
$$

If you have questions regarding your rights as a human subject and participant in this study, you may contact the Ryerson University Research Ethics Board for information.

Alex Karabanow

Project Team Representative

Telephone: 416-979-5000 Ext. 7112

Email: alex.karabanow@ryerson.ca

Research Ethics Board

c/o Office of the Vice President, Research and Innovation

Ryerson University

350 Victoria Street Toronto, ON

M5B 2K3

416-979-5042

Agreement: Your signature below indicates that you have read the information in this agreement and have had a chance to ask any questions you have about the study. Your signature also indicates that you agree to be in the study and that you agree to have the interview audio-taped by the researcher and have been told that you can change your mind and withdraw your consent to participate at any time. You have been given a copy of this agreement.

You have been told that by signing this consent agreement you are not giving up any of your legal rights.

Name of Participant (please print)

Signature of Participant

Date

Signature of Investigator

Date 


\section{Appendix C}

\section{Interview Questions}

Demographic variables: What was your job in China/here? What was your husband's job in China/here? Are you from the city or countryside? Where was your child born? How old is your child? What is the highest education that you have attained? (very informal manner) Values and beliefs shape parenting practices:

What are your beliefs/thoughts/ideas/ about how a child and parent should behave in both public and private places?

What are the child's duties towards his/her family and society in general? What are the parents' duties towards the child?

How do you think that your individual and cultural beliefs have influenced the way you raise your child?

General parenting practices and past relationships

Describe the relationship you had with your parents?

Describe how you care/cared for your child in both a physical and emotional way How did you learn to care for your new baby?

How does/did your child ask for help and love? Or when your child is scared how does he/she ask for help and how do you respond? 


\section{References}

Ali, M. (2008). Loss of parenting self-efficacy among immigrant parents. Contemporary Issues in Early Childhood, 9 (2), 148-160.

Anisef, P., Kilbride, K.M., Ochocka, J., \& Janzen, R. (2001). Study on parenting issues of newcomer families in Ontario. http://atwork. settlement.org / downloads/Parenting_Issues_Overall_Intro.pdf. Retrieved on June 12, 2010.

Baumrind, D. (1978). Parental disciplinary patterns and social competence in children. Youth and Society, 9 (3), 239-276.

Bernhard, J. K. (1995). Child development, cultural diversity, and the professional training of early childhood educators. Canadian Journal of Education, 20 (4), 415-434. http://www.ryerson.ca/ bernhard/documents/temp3.pdf. Retrieved on August, 12, 2010.

Carlson, V.J., \& Harwood, R.L. (2003). Attachment, culture, and the care giving system: The cultural patterning of everyday experiences among Anglo and Puerto Rican mother-infant pairs. Infant Mental Health Journal, 24 (1), 53-73.

Chao, R. (1994). Beyond parental control and authoritarian parenting style: Understanding Chinese parenting through the cultural notion of training. Child Development, 65,1111 1119.

Cheah, C., \& Rubin, K.H. (2003). European American and Mainland Chinese mothers' socialization beliefs regarding preschoolers' social skills. Parenting Science and Practice, $3(1), 1-21$.

Chen, X., Rubin, K. H., Cen, G., Hastings, P., Chen, H., \& Stewart, L. S. (1998). Child-Rearing attitudes and behavioural inhibition in Chinese and Canadian toddlers: A cross-cultural study. Developmental Psychology, 34(4), 677-686 
Chuang, S., \& Su, Y. (2009a). Do we see eye to eye? Chinese mothers' and fathers' parenting beliefs and values for toddlers in Canada and China. Journal of Family Psychology, 23 (3), 331-341.

Chuang, S., \& Su, Y. (2009b). Says who?: Decision-making and conflicts among ChineseCanadian and Mainland-Chinese parents of young children. Sex Roles, 60, 527-536. Creswell, J.W. (2009). Research Design: Qualitative, Quantitative and Mixed Method Approaches, Third Edition.. Thousand Oaks, California: Sage Publications.

Foster, E. S. (2009). Adolescents' experience of adjustment to life with Diabetes: An Interpretative Phenomenological Analysis. (Doctoral dissertation, University of Hertfordshire). https://uhra.herts.ac.uk/dspace/bitstream /2299/ 4519/1/Emily\%20Foster\%20-\%20DClinPsy\%20research\%20thesis.pdf. Retrieved on September 18, 2010.

George, U., Tsang, K., Man, G., \& Da, W. (2000). Needs assessment of Mandarin-speaking newcomers. http://www.settlement.org/downloads/Needs_Mandarin_Speaking _Newcomers.pdf. Retrieved on May 15, 2010.

Guo, S., \& DeVoretz, D. (2005). The changing faces of Chinese immigrants in Canada. http://www.amssa.org/arc/detail.php?resource_id=63. Retrieved on May 1, 2010.

Javo, C., Alapack, R., Heyerdahl, S., \& Rosnning, J.R. (2003). Parental values and ethnic identity in Indigenous Sami families: A qualitative study. Family Process, 42 (1), 151164. 
Jose, P., Huntsinger, C., Huntsinger, P., Liaw, F. (2000). Parental values and practices relevant to Young children's social development in Taiwan and the United States. Journal of CrossCultural Psychology, 31, 677-702.

Keller, H., \& Greenfield P.M. (2000). History and future of development in cross-cultural Psychology. Journal of Cross-Cultural Psychology, 31, 52-62.

Keller, H., Lamm, B., Abels, M., Yovsi, R.D., Borke, J., Jensen, H., Papaligoura, Z.H.C., Holub, C., Tomiyama, A.J., Su, Y., Wang, Y., \& Chaudhary, N. (2006). Cultural models, socialization goals, and parenting ethnotheories: A multicultural analysis. Journal of Cross-Cultural Psychology, 37, 155-172.

Kilbride, K.M. (2000). A review of the literature on the human, social and cultural capital of immigrant children and their families with implications for teacher education. CerisWorking Paper No. 13. http://ceris.metropolis.net/Virtual\%20Library /education/WK\%2013_kilbride.pdf. Retrieved on May 15, 2010.

Lam, C. (2005). Chinese construction of adolescent development outcome: Themes discerned in a qualitative study. Child and Adolescent Social Work Journal, 22 (2), 111-131.

Lay, C., Fairlie, P., Jackson, S., Ricci, T., Eisenberg, J., Sato, T., Teeäär, A., \& Melamud, A. (1998). Domain-Specific Allocentrism-Idiocentrism. Journal of Cross-Cultural Psychology, 29, 434-460.

Lim, S., \& Lim, B. (2004). Parenting style and child outcome in Chinese and immigrant Chinese families current findings and cross-cultural considerations in conceptualization and research. Marriage and Family Review, 35 (3), 21-43. 
Lim, S., \& Wieling, E. (2004). Immigrant Chinese American women negotiating values and perceptions of self in the cultural borderlands of east and west: A qualitative study. The Family Journal, 12, 148-158.

Lin, C., \& Fu, V. (1990). A comparison of child rearing practices among Chinese, immigrant Chinese, and Caucasian-American parents. Child Development, 61, 429-433.

Liu, G., Guo, F. (2010). Parenting practices and their relevance to child behaviours in Canada and China. Scandinavian Journal of Psychology, 51, 109-114.

Liu, L. (2009). Double transitions, double learning: Chinese immigrants and child rearing. Ontario Institute for Studies in Education of the University of Toronto. .http://www.oise.utoronto.ca/CASAE/cnf2009/OnlineProceedings-2009/Papers/Liu.pdf. Retrieved on August 15, 2010.

Liu, M., Chen, X., Rubin, K., Zheng, S., Cui, L., Li, d., Chen, H., \& Wang, L. (2005). Autonomy vs. connectedness-orientated parenting behaviours in Chinese and Canadian mothers. International Journal of Behavioral Development, 29 (6), 489-495.

Mel'endez, L. (2005). Parental beliefs and practices around early self-regulation: The impact of culture and immigration. Infants and Young Children, 18 (2), 136-146.

Morse, J. M., Barrett, M., Mayan, M., Olson, K., \& Spiers, J. (2002). Verification strategies for establishing reliability and validity in qualitative research. International Journal of Qualitative Methods, 1(2), 1-19. http://www.ualberta. ca/ iiqm/ backissues/1_2Final/pdf/morseetal.pdf. Retrieved on September 17, 2010.

Portes, A., \& Borocz, J. (1989). Contemporary immigration: Theoretical perspectives on its determinants and modes of incorporation. International Migration Review, 23 (3), 606630. 
Ratner, C. \& Hui, L. (2003). Theoretical and methodological problems in cross-cultural psychology. Journal for the Theory of Social Behaviour, 33 (1), 68-94.

Reid, K., Flowers, P., \& Larkin, M. (2005). Exploring lived experience. Psychologist, 18, 1, 2023.

Ritchie, J., \& Lewis, J. (2003). The foundations of qualitative research. In D. Snape and L. Spencer (Eds.), Qualitative Research Practice (pp. 1-22). London: Sage Publications. Rogoff, B. (2003). Cultural nature of human development. http://site.ebrary.com/lib/oculryerson/ Doc?id= 10084 747\&ppg $=345$ Retrieved on August 15, 2010.

Smith, J.A., Flowers, P., \& Larkin, M. (2009). Interpretative Phenomenological Analysis.London: Sage Publications.

Statistics Canada (2003). Visible minority population summary table. Available on line at http://www40.statcan.gc.ca/101/cst01/demo50a-eng.htm. Retrieved on May 21. 2010.

Su, T. F., \& Costigan, C. L. (2009). The development of children's ethnic identity in immigrant Chinese families in Canada: The role of parenting practices and children's perceptions of parental family obligations. Journal of Early Adolescence, 29, 638-663.

Tamminen, T. (2006). How does culture promote the early development of identity? Infant Mental Health Journal, 603-605.

Willig, C. (2001). Introducing qualitative research in psychology: adventures in theory and method. Maidenhead, England: Open University Press.

Yardley, L. (2000). Dilemmas in qualitative health research. Psychology and Health, 15, 215228. 